\title{
Development of Implantable Medical Devices: From an Engineering Perspective
}

\author{
Yeun-Ho Joung \\ Department of Electronics and Control Engineering, Hanbat National University, Daejeon, Korea
}

\begin{abstract}
From the first pacemaker implant in 1958, numerous engineering and medical activities for implantable medical device development have faced challenges in materials, battery power, functionality, electrical power consumption, size shrinkage, system delivery, and wireless communication. With explosive advances in scientific and engineering technology, many implantable medical devices such as the pacemaker, cochlear implant, and real-time blood pressure sensors have been developed and improved. This trend of progress in medical devices will continue because of the coming super-aged society, which will result in more consumers for the devices. The inner body is a special space filled with electrical, chemical, mechanical, and marine-salted reactions. Therefore, electrical connectivity and communication, corrosion, robustness, and hermeticity are key factors to be considered during the development stage. The main participants in the development stage are the user, the medical staff, and the engineer or technician. Thus, there are three different viewpoints in the development of implantable devices. In this review paper, considerations in the development of implantable medical devices will be presented from the viewpoint of an engineering mind.
\end{abstract}

Keywords: Biomedical engineering; Medical electronics; Micro-electro-mechanical systems; Biocompatible materials

\section{INTRODUCTION}

A medical device is defined as implantable if it is either partly or totally introduced, surgically or medically, into the human body and is intended to remain there after the procedure [1-2]. Jiang and Zhou [3] have described that $8 \%$ to $10 \%$ of the population in America and 5\% to 6\% of people in industrialized countries have experienced an implantable medical device for rebuilding body functions, achieving a better quality of life, or expanding longevity.

In the past six decades, implantable medical devices or systems have been advanced through developments in science and engineering, especially in microelectronics, biotechnology, and materials. From Zoll's first report [4] on electrical heart stimulation in 1952 to the first commercialized wireless blood pressure measurement system introduced by Cardiomems in 2010, med- ical experts have exerted honorable efforts to improve the quality of patients' lives with various medical devices, such as the implantable cardiac defibrillator, cochlear implant, implanted bladder stimulator, and implantable wireless pressure sensor [517]. Such implantable medical devices were developed to sense a physiological response in vivo or to actuate physiological organs. Recently, with the superminiaturization of electronic circuits and mechanical structures, many researchers have focused on the development of implantable real-time vital monitoring systems, which are continuously operated in subsecond periods [18-21]. The implantable real-time vital monitoring devices may shift medical systems from remedying incidents after they occur to self-managing incidents before they occur. For example, the EndoSure of Cardiomems, which is inserted into the aorta to measure intrasac pressure during endovascular abdominal aortic aneurysm repair and during endovascular thoracic
Corresponding author: Yeun-Ho Joung

Department of Electronics and Control Engineering, Hanbat National University, 125 Dongseo-daero, Yuseong-gu, Daejeon 305-719, Korea Tel: +82-42-420-4852 / Fax: +82-42-820-4853 / E-mail: yeunho@gmail.com Submitted: September 16, 2013 / Accepted after revision: September 26, 2013
This is an Open Access article distributed under the terms of the Creative Commons Attribution Non-Commercial License (http://creativecommons.org/licenses/by-nc/3.0/) which permits unrestricted non-commercial use, distribution, and reproduction in any medium, provided the original work is properly cited. 
aortic aneurysm repair, can detect intraoperative leaks of the stent graft. After discharge from the hospital, patients can check the intrasac pressure daily at home, which was traditionally monitored by an angiographic method only at a hospital [22].

The first fully implantable pacemaker was encapsulated by araldite epoxy resin. In the polymer encapsulation, a low power consumption first-generation silicon transistor (OC460) integrated with electrical circuits was packaged with two sealed 60 $\mathrm{mAh}$ nickel-cadmium battery cells. The electrical circuit was connected with an inductive coil for recharging the batteries. The electrical-pulse-generating system was connected with electrodes via stainless steel wire covered with polyethylene. The total size of the first implantable pacemaker was $55 \mathrm{~mm}$ in diameter and $16 \mathrm{~mm}$ in thickness, similar to the dimensions of a shoe polish can from British Kiwi [10].

From the old machine, we could read the engineer's intentions to develop the most valuable device for human beings. In the early stages of the silicon-based transistor, the semiconductor technology was not high-tech enough to handle micron-level sizes. After metal-oxide-semiconductor field-effect-transistor was invented, the shrinkage race for transistor size was initiated with the spreading of cleanroom facilities in the 1960s. In 1971, Intel had adopted a $10-\mu \mathrm{m}$ manufacturing technology, and in 2012, the company applied a 22-nm line width technology on the Xeon E3-1230 [23-25]. The 22-nm node technology can produce approximately 500 transistors on an area, which is occupied by a $10-\mu \mathrm{m}$ node transistor. Through advancements in semiconductor technology, smaller, lighter, and multipurpose electronic devices became available. Diminishment in the electronic circuit resulted in other advantages in battery lifetime and capacity [26]. In 1973, Greatbatch and Holmes [5] developed lithium-iodine batteries, which have good characteristics for use in the smaller and lighter electronic systems, such as a long lifetime, low current drain, and static voltage output. In the early era of pacemaker implants, artificial heart pulses were transferred to the myocardium via a stainless steel lead. On October 9, 1958, the Swedish physician Senning (quoted from [7]) implanted a second pacemaker unit that functioned well for only 7 days. Suddenly, the amplitude of the pacemaker stimulus was gradually decreased by a fracture in the stainless steel lead. After figuring out the inferior mechanical and chemical properties of stainless steel in the human body, many researchers attempted to replace the lead configuration with different materials, such as alloys of cobalt, chromium, and nickel [7]. However, those old-generation pacemaker leads had limitations such as high fracture rates, dislodgement, electromagnetic interference, high capture thresholds, and corrosion [27]. The lead-related issues were finally solved by the use of materials such as silicone or polyurethane-insulated noble metal coils of platinum and iridium or titanium [8].

The epoxy resin encapsulation of the first-generation pacemaker was developed to protect the electronic circuits and batteries from body fluid penetration and tissue invasion to the system. Also, the encapsulation or housing worked as a barrier between the human body and hazardous batteries. However, the polymer-based epoxy resin swelled and dissolved inside the human body [28-30]. Thus, the housing materials had to be replaced with ceramics and titanium to protect the electrical systems. Currently, the electric elements and a battery are packaged by a laser welding of titanium, which has a strong mechanical hardness, extreme resistance to corrosion, biocompatibility, and durability [31,32]. Electrical connections between the metalhoused electronic system and the lead wire of the pacemaker induced another sealing issue. Owing to the metallic housing, the electrical signal output part, which is connected to the lead, should be passivated by an insulator to prevent electrical connection to the metal housing. Therefore, polymer- or ceramicbased electrical feedthrough was developed with perfect separation between the electronic system and the human body environment.

The first operation for implanting a pacemaker was done by the surgeon Ake Senning, who performed an open thoracotomy and suturing of 9-mm diameter electrodes on the left side of the myocardium. Afterward, the heart pace was electrically controlled for 3 hours. The next operation happened on following day and the device worked for 7 days. Currently, the pacemaker implant procedure takes around 1 to 2 hours with 4 - to 5-mm diameter electrodes fixed on the right ventricle and the right atrium. One day after the operation, the patient is released from the hospital and can enjoy his or her regular life again with the help of the pacemaker. The small size and lightweight main body of the pacemaker allow the patient to avoid openheart surgery, and the flexible platinum lead coils make an easy and short procedure possible [7].

Through this rough comparison between first-generation and modern pacemakers, the progress of the iconic implantable medical device was reviewed with an engineering mind. More detailed engineering considerations in the development of implantable medical devices will be described in the following sections. 


\section{GENERAL THOUGHTS ON IMPLANTABLE MEDICAL DEVICES}

The designing of an implantable medical device is initiated with information gathering from three main participants: the patient, the medical staff, and the engineer. That is, the development of the device is highly influenced by the demands of patients, the preferences of medical doctors, and the realistic feasibility of the design as envisioned by the engineer. In general, patients who are in possession of a device either temporarily or permanently feel discomfort owing to the foreign object and have the expectation that the medical procedure be performed quickly without pain and that the healing procedure be accomplished unconsciously. Many efforts are needed to resolve these issues. Through the advent of minimally invasive medical procedures and the advanced shrinkage of the devices, the insertion site has become unnoticeable and restoration can occur unconsciously. A high-power-density battery made of lithium-iodine polyvinylpyridine, lithium-carbon monofluoride, or lithium-polycarbon fluoride gives a longer device-replacement interval to the patient [33-35]. After the implantation, programmed or designed functions of the devices work automatically. Consumers of the devices want to know whether the device is working properly, and they like to check the results of the device functioning without any special medical treatment, such as magnetic resonance imaging, computed tomography, or X-ray. Thus, the easy operation procedure, less invasive implantation, better healing performance, longer replacement timetable, and easy access to vital status results in a better quality of life of the consumers.

The medical doctor is a user, a reviewer, and a researcher of medical devices. Physicians need to know how to implant, where to implant, when to implant, and why to implant. They have heard many pathetic cases from patients and have met unexpected surgical situations owing to the different structure of the human body. Fortunately, they have studied the structure, elements, and function of the human body. They are often the ones to propose an initial design concept to the patient and engineer. The size and shape of the medical device should be considered to fit the implantation spot in the human body. If the spot is not large enough to contain the whole device, the device can be designed so that it is separated into elements, e.g., electrodes and a stimulator in a cochlear implant, or so that discrete elements are connected, e.g., the pressure sensor and battery in the blood pressure sensor of Frounhofer [36]. The size and shape of the device also affect the delivery method of the device. If the total size of the device is too large for use in insertion tools like a catheter, incision surgery is required for insertion. For the stent-sized medical system, which is smaller than the human organ, a delivery system through minimally invasive surgery should be created or invented. If the device is small enough to fit in a conventional needle size, we can deliver the device by needle injection.

After delivery or implantation of the devices, the human body reacts to the unfamiliar material and starts to attack the material with antibiotics. In this case, neointimal tissue or fibrocellular shields can separate the device from the original tissue. If the device is packaged or encapsulated by material that is not biocompatible, the immune response elicits severe electrical and chemical reactions with the material. Therefore, the biocompatibility of the packaged material has to be confirmed by animal study and good manufacturing practice before implantation.

The human body is an extraordinary environment to the engineer. The new space always has a constant temperature of $36.5^{\circ} \mathrm{C}$, is continuously changed by electrical and chemical reactions, and is vulnerable to being extinguished by a tiny modification of a body element. The arcane space should be approached very ethically, logically, and scientifically. In general, medical devices are engineered to restore a body function, to detect a body signal, or to provide mechanical or electrical assistance to a human organ. Therefore, engineers need to acquaint themselves with the human body in terms of environment, functionality, structure, and biological reactions. On the basis of this study, they begin to assemble their knowledge in engineering fields, such as biocompatibility, electronic circuits, micro-electro-mechanical systems, hermeticity or packaging, wireless or wired communications, securities, batteries, insertion tools, and so on. Then, the manufacturing feasibility of a special device has to be checked through modeling and through realistic testing. The manufactured system is tested on the benchtop and put into living things. The manufacturing and testing processes are continued until proper devices are obtained. During those processes, the engineers meet challenges in the following categories: biocompatibility, hermeticity, structural design, delivery system, power management, detection, and wireless communication.

\section{ENGINEER'S CONSIDERTIONS FOR IMPLANTABLE MEDICAL DEVICES}

\section{Biocompatibility}

When the medical device is implanted in the human body, the 
surrounding environment immediately responds to the material itself or to microorganisms on the surface of the device. During the initial stage, nonspecific blood and tissue fluid proteins cling to or penetrate the materials. Then, immune and inflammatory cells, such as monocytes, leukocytes, and platelets, react to defend the body from the external specimen [37-39]. If the abiotic material is not well matched with the tissues and cells, it is hard for the system to remain in place long term and it could result in an unsafe effect on the body.

It is also important to consider treatment of the microorganisms on the material surface. Usually, implantable medical devices should be sterilized to eliminate harmful microorganisms before implantation. The various sterilization methods for medical devices include dry heat sterilization, pressured vapor sterilization, ethylene oxide sterilization (EtO), formaldehyde sterilization, gas plasma $\left(\mathrm{H}_{2} \mathrm{O}_{2}\right)$ sterilization, peracetic acid sterilization, gamma radiation sterilization, and E-beam sterilization [40-43]. For the class III of medical devices in the U.S. Food and Drug Administration classification, EtO, gamma radiation, and E-beam sterilization are recommended. Actively operated implantable medical devices such as the pacemaker, implantable cardioverter defibrillator (ICD), and cochlear implants are perfectly sealed by biocompatible materials. In the selection of a biocompatible material, the sealing feasibility should be considered. To date, effective biocompatible materials can be reported as follows: titanium and its alloys, noble metals and their alloys, biograde stainless steels, some cobalt-based alloys, tantalum, niobium, titanium-niobium alloys, Nitinol, MP35N (a nickelcobalt-molybdenum alloy), alumina, zirconia, quartz, fused silica, biograde glass, silicon, and some biocompatible polymers [44-55].

\section{Packaging and Hermeticity}

The microelectronic system is operated by electrical connections between electronic components. At the final stage of electronic chip manufacturing, the electronics parts are packaged under a vacuum to prevent degradation of the electrical performance of the components through exposure to the air. Like the microelectronic chip, implantable medical devices need a protective barrier from inner body elements such as cells, proteins, platelets, and chemical gases. Moreover, the packaging has another functionality of trapping the outgas of the inner materials. That is, the packaging should perfectly isolate the inner electrical and mechanical components from the human body environment. If the isolation is airtight, then we can say that the package

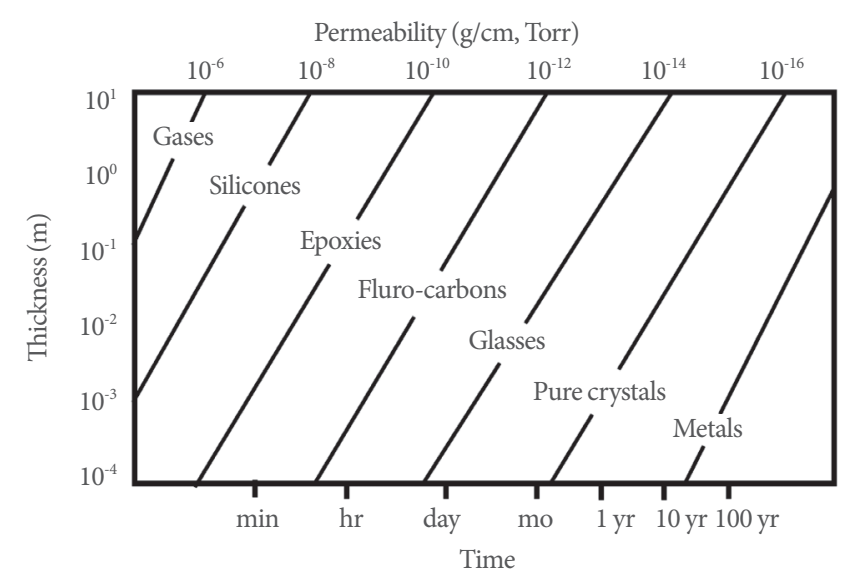

Fig. 1. Material-dependent permeability. The graph shows also permeability as a function of thickness.

is hermetically sealed. MIL-STD-883, Method 1014.10, which has been adapted by the medical device industry, provides details of the hermeticity testing procedure. The most common hermeticity measurement is performed by use of a helium leak detector, which is a mass spectrometer designed to analyze helium gas. Fig. 1 shows the helium gas permeability of common medical device materials. The figure also shows the projected lifetimes of the materials as a function of the thickness of the material.

The packaging of implantable medical devices is done by use of various materials, such as quartz, fused silica, polymers, metals, and ceramics [56-63]. Packaging of the system encloses the electronic or mechanical system by encapsulation of the polymer and welding or bonding of the metal, glass, and ceramics. Materials of the polymer encapsulation package include epoxies, silicones, polyurethanes, polyimides, silicon-polyimides, parylenes, polycyclic-olefins, silicon-carbons, benzocyclobutenes, and liquid crystal polymers. Silicone rubber has been used for the encapsulation layer for artery line pressure sensors, epoxies have been used to cover the feedthrough connections in ICDs, and polyurethanes have been used to cover platinum wires in the pacemaker. Glass type packages based on quartz, fused silica, and borosilicate are generally completed by melting of the glasses done by local laser-focused heating. The glass packaging method is used for neuromuscular stimulators, radio frequency identification chips, endoscope pills, and implantable blood pressure sensors. The metallic package is the most common hermetic packaging method and is accomplished by laser welding of the metals. The metallic package is applied for loop recorders, pacemakers, ICDs, and cochlear implants. 


\section{Structural Design of Implantable Devices and Delivery Systems}

The human body is a complex system operated by mechanical, chemical, and electrical mechanisms of numerous organs, tissues, and cells. Furthermore, the system has different shapes, sizes, placement, functionality, and reactions according to age, sex, and race. Therefore, it is difficult to design the whole structure of the medical device at once. Design requires abundant research reviews, mathematical simulations, and benchtop testing with a phantom of the human body, animal studies, and real implants. During the developmental stage, the engineer will meet scientific, biological, and medical impasses. If an electronic device is adequate for handling the electronic data but the chip is too large to insert in the human body, then we should find a substitute electronic chip or totally rework the concept.

In general, actively working implantable devices such as implantable blood pressure measurement devices require an energy source for data processing and wireless communication in battery form. To guarantee the power requirement for the duration of operation, a battery with the proper capacity has to be integrated with the electronic system. However, it is hard to find an appropriate commercial battery. Up to now, finding the battery has been a bottleneck in arterial blood pressure measurement system development. For example, Frounhofer's blood pressure measurement system is assembled with an inner-arterial pressure sensor and an outer-arterial battery.

As mentioned in the previous section, the delivery methods

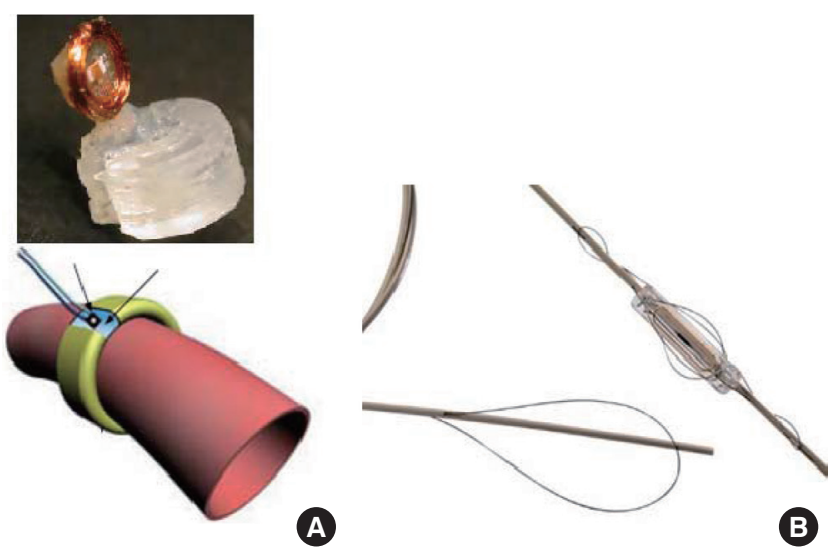

Fig. 2. Implantable blood pressure sensor. (A) Surgically implanted blood pressure sensor with a cuff-type design. The sensor is installed on the blood vessel directly. (B) Cardiomems implantable blood pressure sensor. The sensor is paced in the target position by use of a delivery system. The sensor is delivered by the same procedure with a stent. of the devices can be broadly defined as two categories: incision and tools. A review of the literature shows two methods of implantable blood pressure measurements: inner-artery blood pressure measurement and outer-artery blood pressure measurement. Both methods can be described as an implantable direct artery blood pressure measurement, but the measurement spot differs. As shown in Fig. 2, sensors developed by Cong et al. [64] are installed around the artery for good mechanical contact with the artery. This system should be inserted by incision. Another method can be found in a commercialized Cardiomems sensor [17]. As shown in Fig. 2B, the Cardiomems sensor has a rectangular shape with a narrow width and Nitinol springs to fix the sensor in the artery. Cardiomems has a delivery system that uses catheters of $4-5 \mathrm{~mm}$ in diameter. In the first stage of development, Cardiomems selected the delivery positions of the sensor, and researchers in the company designed the sensor and delivery system simultaneously.

One more thing to consider in device design is the performance of the devices. In general, implantable medical devices are inserted when the patient positively needs the device. In other words, the implantable device is a last hope for the patient. Thus, the performance of the device is the most important factor in the design.

\section{Power Management}

Electric power supplements to implantable medical devices are a barrier in the design scheme of the devices owing to their limited size and demands of high capacity. There are two types of implantable batteries: single-use and rechargeable [65-70]. ICDs, pacemakers, and deeply implanted stimulators have one-timeuse batteries. Cochlear implants, replacement heart implants, and retinal prostheses have continuously chargeable batteries. The single-use battery should be changed by operation when the electrical power is not enough to properly operate the device. The remaining capacity of the power in a nonrechargeable battery is regularly checked by wireless inductive telemetry [7173]. The wireless telemetry in medical devices was originally used to power the first-generation pacemakers. However, the real-time power transmission to the devices was inefficient and the wearing of an external power-transferring coil was uncomfortable for the patients. Wireless telemetry is composed of an inner-body receiving coil and an extracorporeal power sending system. When the energy-containing frequency is fed to the external coil, the coil generates magnetic fields within some distance. If the inner inductor coil is almost perpendicularly placed 
to the external coil within range, the magnetic flux makes current flow through the inner coil and induces uniform electrical voltage by rectification and regulation. Then, the rechargeable battery is replenished by the voltage. However, if the distance between the inner and outer coils is too far or relatively long to set up proper inductive coupling, it is impossible to induce any current or a very weak current is generated.

Recently, much research has been focused on energy generation by using physical, chemical, mechanical, and electrical phenomena of the inner body to resolve the energy issue of implantable devices. The technology is called "energy harvesting" or "energy scavenging" [74-79]. Energy harvesting can be easily found from a self-winding wristwatch, shake-driven flashlight, bicycle dynamo, and the latest fashioned lever-driven phone charger. Goto et al. [80] have used the self-winding wristwatch mechanism to supply energy to pacemakers. Mazzilli et al. [81] have tried to transfer energy by ultrasound generated by a 64-channel high-voltage driver. Those energy generation methods still demand a battery to store the induced electrical charge like a conventional rechargeable one. Kerzenmacher et al. [82] used a different approach to generate energy for the device. They used glucose as a catalyst to oxidize noble metals or carbon. However, the energy harvesting methods have commonly produced very low instant energy output levels with poor efficiency, which has restricted them from being used as a direct energy source. In other words, the technology is not yet free from the energy storage system.

\section{Detection or Wireless Communication}

The implantable medical device is an extremely crucial system. Without such devices, many persons have hardships in vision, hearing, acute pain, or cardiac disorder. Thus, the functionality of the device should be closely monitored. For surveillance or monitoring of the device, extraction of the device or wired electrical connection to the device is only a second choice. Wireless communication is the first choice. Wireless communication transfers data or signals at some distance without the aid of wire. The transfer efficiency varies by media. Generally, the signal is easily dispersed in a conductive media. If the frequency is higher, as much as a giga-hertz, the dissipation rate of the frequency is relatively higher. Therefore, the US Federal Communications Commission and European Telecommunications Standards Institute have defined the Medical Implants Communication Services band (402-405 MHz) as the implantable medical device frequency range $[83,84]$. Wireless communica- tion can be successful when the wireless chip is packaged by nonmetallic or nonconductive materials. Thus, it is hard to find actively operated wireless communication systems for implantable medical devices. Compared with the active wireless communicated medical system, passively communicated or inductively coupled communicated medical devices have been relatively well developed. As mentioned in the previous section, the pacemaker and ICD transfer data on residual energy status to an external detection system. The pressure sensor of the Cardiomems gives data to an external system when an external antenna is placed in an inductively coupling distance with the sensor [85]. This passive type has a relatively low operating frequency in the range of a few hundreds $\mathrm{kHz}$ to tens of $\mathrm{MHz}$. However, noise is easily produced by inductive coupling with other metal structures surrounding the measurement system. Because the energy to operate sensors is transferred by inductive coupling, the system is workable without a battery, but it is hard to continuously measure or communicate.

\section{CONCLUSIONS}

In this article, considerations in the development of implantable medical devices were reviewed from an engineering viewpoint. By tracing pacemaker development from the first generation of devices in 1958 to current devices, the historical advancement of the medical device was roughly described. There are three participants in the development of medical devices, and gathering information from each of them is crucial. Users demand minimally invasive operations that enable them to be released from a medical facility quickly with lower expense. Medical staffs propose the necessity of the medical device owing to their expertise about the human body in terms of size, functionality, position, and medical approaches. Engineers pour their technical knowledge into the practical design of the devices. They cooperate with medical staff in designing the shape, size, functionality, and method of delivering. Biocompatibility and durability of the material exposed to the inner body environment must be guaranteed by a series of laboratory experiments, animal studies, and so on. Electrical and mechanical devices are hermetically packaged by use of a biocompatible material to establish a perfect barrier between the device and inner body components such as body fluids, cells, and tissues. With the knowledge of advanced technology, structures of the device and the delivery system should be designed by assistance from the user and medical staff. Many simulations, prototypes, and testing help to ob- 
tain the best device. The electrical power source is carefully designed to get a suitable shape and the power supply is continuously monitored to ensure uninterrupted operation. For realtime monitoring of the human body, active or passive wireless communication methods are selected with contestation of packaging material, power, and detection interval. Compared with the well-known space, atmospheric, and marine environments, the inner body is an unfamiliar and underdeveloped space to the engineer. Developing medical devices for the human body must be initiated by an understanding of the environment, that is, a human being.

\section{CONFLICT OF INTEREST}

No potential conflict of interest relevant to this article was reported.

\section{ACKNOWLEDGEMENTS}

This research was supported by the Innovative Technology Development Program funded by the Small and Medium Business Administration of Korea (S2105913).

\section{REFERENCES}

1. ISO 13485:2003. Medical devices -- Quality management systems -- Requirements for regulatory purposes [Internet]. Geneva: Switzerland; [cited 2013 Jun 15]. Available from: http://www.iso.org/ iso/catalogue_detail?csnumber $=36786$.

2. Johnson JA. FDA regulation of medical devices. Congressional research service, June 25, 2012 [Internet]. Washington, DC: Federation of American Scientists; c2013 [cited 2013 Jul 13]. Available from: http://www.fas.org/sgp/crs/misc/R42130.pdf.

3. Jiang G, Zhou DD. Technology advances and challenges in hermetic packaging for implantable medical devices. In: Zhou DD, Greenbaum ES, editors. Implantable neural prostheses 2: techniques and engineering approaches. Berlin: Springer; 2010. p. $28-61$.

4. Zoll PM. Resuscitation of the heart in ventricular standstill by external electric stimulation. N Engl J Med 1952;247:768-71.

5. Greatbatch W, Holmes CF. History of implantable devices. IEEE Eng Med Biol Mag 1991;10:38-41.

6. Magjarevic R, Ferek-Petric B. Implantable cardiac pacemakers: 50 years from the first implantation. Zdrav Vestn 2010;79:55-67.

7. Larsson B, Elmqvist H, Ryden L, Schuller H. Lessons from the first patient with an implanted pacemaker: 1958-2001. Pacing Clin
Electrophysiol 2003;26(1 Pt 1):114-24.

8. Beck H, Boden WE, Patibandla S, Kireyev D, Gutpa V, Campagna F, et al. 50th Anniversary of the first successful permanent pacemaker implantation in the United States: historical review and future directions. Am J Cardiol 2010;106:810-8.

9. Rajappan K. Permanent pacemaker implantation technique: part II. Heart 2009;95:334-42.

10. Fiandra O. The first pacemaker implant in America. Pacing Clin Electrophysiol 1988;11:1234-8.

11. Furman S. Early history of cardiac pacing and defibrillation. Indian Pacing Electrophysiol J 2002;2:2-3.

12. Kileny PR, Zimmerman-Phillips S, Kemink JL, Schmaltz SP. Effects of preoperative electrical stimulability and historical factors on performance with multichannel cochlear implant. Ann Otol Rhinol Laryngol 1991;100:563-8.

13. Wilson BS, Dorman MF. Cochlear implants: a remarkable past and a brilliant future. Hear Res 2008;242:3-21.

14. Shlegr Z, Egorov A. Implantable electric bladder stimulator used for neurogenic failures. Biomed Eng (NY) 1974;7:382-3.

15. Majerus SJ, Fletter PC, Damaser MS, Garverick SL. Low-power wireless micromanometer system for acute and chronic bladderpressure monitoring. IEEE Trans Biomed Eng 2011;58:763-7.

16. Axisa F, Jourand P, Lippens E, Rymarczyk-Machal M, De Smet N, Schacht E, et al. Design and fabrication of a low cost implantable bladder pressure monitor. Conf Proc IEEE Eng Med Biol Soc 2009; 2009:4864-7.

17. Mokwa W. Medical implants based on microsystems. Meas Sci Technol 2007;18:R47-57.

18. Narasimhan S, Wang X, Bhunia S. Implantable electronics: emerging design issues and an ultralight-weight security solution. Conf Proc IEEE Eng Med Biol Soc 2010;2010:6425-8.

19. Bazaka K, Jacob MV. Implantable devices: issues and challenges. Electronics 2013;2:1-34.

20. Chua-Chin Wang, Chi-Chun Huang, Jian-Sing Liou, Yan-Jhin Ciou, I-Yu Huang, Chih-Peng Li, et al. A mini-invasive long-term bladder urine pressure measurement ASIC and system. IEEE Trans Biomed Circuits Syst 2008;2:44-9.

21. Olivo J, Carrara S, De Micheli G. Energy harvesting and remote powering for implantable biosensors. IEEE Sens J 2011;11:1573-86.

22. Parsa CJ, Williams JB, Bhattacharya SD, Wolfe WG, Daneshmand MA, McCann RL, et al. Midterm results with thoracic endovascular aortic repair for chronic type B aortic dissection with associated aneurysm. J Thorac Cardiovasc Surg 2011;141:322-7.

23. Sugii T, Watanabe K, Sugatani S. Transistor design for $90 \mathrm{~nm}$-generation and beyond. Fujitsu Sci Tech J 2003;39:9-22. 
24. Intel's $22 \mathrm{~nm}$ Technology Moves Transistor Into the 3rd Dimension [internet]. Santa Clara: Intel Co., [cited 2013 Sep 5]. Available from: http://www.intel.com/content/www/us/en/silicon-innovations/ standards-22-nanometers-technology-backgrounder.html.

25. Kuhn KJ, Liu MY, Kennel H. Technology options for $22 \mathrm{~nm}$ and beyond. Proceeding of the 10th International Workshop on Junction Technology (IWJT-2010); 2010 May 10-11; Shanghai, China.

26. Mallela VS, Ilankumaran V, Rao NS. Trends in cardiac pacemaker batteries. Indian Pacing Electrophysiol J 2004;4:201-12.

27. Burri H, Sunthorn H, Shah D. Complications of pacemaker leads. Heart 2003;89:1421.

28. Chirife R, Frankl WS, Mendizabal R, Estioko MR. Ventricular fibrillation induced by a defective demand pacemaker. Chest 1976; 69:247-9.

29. Gerdsen R, Kaiser HW, Friedrich K, Rabe E, Bieber T. Annular erythema caused by impending pacemaker extrusion. Acta Derm Venereol 1999;79:385-7.

30. Davies JG, siddons H. Experience with implanted pacemakers: technical considerations. Thorax 1965;20:128-34.

31. Kramar T, Michalec I, Kovacocy P. The laser beam welding of titanium grade 2 alloy, GRANT J. 2012;1:77-9.

32. Waurzyniak P. With the latest precision lasers, manufacturers build life-saving medical devices. Manuf Eng 2010;144:1-4.

33. Greatbatch W, Holmes CF. The lithium/iodine battery: a historical perspective. Pacing Clin Electrophysiol 1992;15(11 Pt 2):2034-6.

34. Chen K, Merritt DR, Howard WG, Schmidt CL, Skarstad PM. Hybrid cathode lithium batteries for implantable medical applications. J Power Sources 2006;162:837-40.

35. Aifantis KE, Hackney SA, Vasant Kumar R, editors. High energy density lithium batteries: materials, engineering, applications. Weinheim: Wiley-VCH; 2010.

36. Grafe M, Gottsche T, Osypka P, Gortz M, Trieu HK, Fassbender H, et al. HYPER-IMS: a fully implantable blood pressure sensor for hypertensive patients. SENSOR 2009: Proceedings of 14th International Conference on Sensors, Technologies, Electronics and Applications. Vol.1: 2009 May 26-28; Nürnberg, Germany. Wunstorf: AMA Service; 2009. p. 145-9.

37. Onuki Y, Bhardwaj U, Papadimitrakopoulos F, Burgess DJ. A review of the biocompatibility of implantable devices: current challenges to overcome foreign body response. J Diabetes Sci Technol 2008;2:1003-15.

38. Cameron T, Liinamaa TL, Loeb GE, Richmond FJ. Long-term biocompatibility of a miniature stimulator implanted in feline hind limb muscles. IEEE Trans Biomed Eng 1998;45:1024-35.

39. Williams DF. On the mechanisms of biocompatibility. Biomaterials
2008;29:2941-53.

40. Tilton G, Kauffman M. Sterilization: a review of the basics. Manag Infect Control 2004:66-71.

41. Silindir M, Ozer AY. Sterilization methods and the comparison of E-Beam sterilization with gamma radiation sterilization. FABAD J Pharm Sci 2009;34:43-53.

42. Lambert BJ, Mendelson TA, Craven MD. Radiation and ethylene oxide terminal sterilization experiences with drug eluting stent products. AAPS PharmSciTech 2011;12:1116-26.

43. Ahmed S, Rigby GP, Crump P, Vadgama PM. Comparative assessment of chemical and gamma-irradiation procedures for implantable glucose enzyme electrodes. Biosens Bioelectron 2000;15:159-65.

44. Schuettler M, Schatz A, Ordonez JS, Stieglitz T. Ensuring minimal humidity levels in hermetic implant housings. Conf Proc IEEE Eng Med Biol Soc 2011;2011:2296-9.

45. Antunes RA, de Oliveira MC. Corrosion fatigue of biomedical metallic alloys: mechanisms and mitigation. Acta Biomater 2012;8: 937-62.

46. Witte F. The history of biodegradable magnesium implants: a review. Acta Biomater 2010;6:1680-92.

47. Antunes RA, de Oliveira MC. Corrosion processes of physical vapor deposition-coated metallic implants. Crit Rev Biomed Eng 2009;37: 425-60.

48. von Metzen RP, Stieglitz T. A wireless system for monitoring polymer encapsulations. Conf Proc IEEE Eng Med Biol Soc 2007;2007: 6601-4.

49. Jiang G, Mishler D, Davis R, Mobley JP, Schulman JH. Zirconia to Ti-6Al-4V braze joint for implantable biomedical device. J Biomed Mater Res B Appl Biomater 2005;72:316-21.

50. Mailley S, Hyland M, Mailley P, McLaughlin JA, McAdams ET. Thin film platinum cuff electrodes for neurostimulation: in vitro approach of safe neurostimulation parameters. Bioelectrochemistry 2004;63:359-64.

51. Thierry B, Tabrizian M. Biocompatibility and biostability of metallic endovascular implants: state of the art and perspectives. J Endovasc Ther 2003;10:807-24.

52. Catledge SA, Fries MD, Vohra YK, Lacefield WR, Lemons JE, Woodard S, et al. Nanostructured ceramics for biomedical implants. J Nanosci Nanotechnol 2002;2:293-312.

53. Placko HE, Mishra S, Weimer JJ, Lucas LC. Surface characterization of titanium-based implant materials. Int J Oral Maxillofac Implants 2000;15:355-63.

54. Bundy KJ. Corrosion and other electrochemical aspects of biomaterials. Crit Rev Biomed Eng 1994;22:139-251.

55. Bruck SD. Biostability of materials and implants. J Long Term Eff 
Med Implants 1991;1:89-106.

56. Chlebowski AL, Chow EY, Ellison C, Irazoqui PP. Integrated LTCC packaging for use in biomedical devices. Biomed Mater Eng 2012; 22:361-72.

57. Kim SJ, Lee DS, Kim IG, Sohn DW, Park JY, Choi BK, et al. Evaluation of the biocompatibility of a coating material for an implantable bladder volume sensor. Kaohsiung J Med Sci 2012;28:123-9.

58. Schuettler M, Ordonez JS, Silva Santisteban T, Schatz A, Wilde J, Stieglitz T. Fabrication and test of a hermetic miniature implant package with 360 electrical feedthroughs. Conf Proc IEEE Eng Med Biol Soc 2010;2010:1585-8.

59. Chen GQ. Biofunctionalization of polymers and their applications. Adv Biochem Eng Biotechnol 2011;125:29-45.

60. Kazemi M, Basham E, Sivaprakasam M, Wang G, Rodger D, Weiland J, et al. A test microchip for evaluation of hermetic packaging technology for biomedical prosthetic implants. Conf Proc IEEE Eng Med Biol Soc 2004;6:4093-5.

61. Guenther T, Dodds CW, Lovell NH, Suaning GJ. Chip-scale hermetic feedthroughs for implantable bionics. Conf Proc IEEE Eng Med Biol Soc 2011;2011:6717-20.

62. Zeng FG, Rebscher S, Harrison W, Sun X, Feng H. Cochlear implants: system design, integration, and evaluation. IEEE Rev Biomed Eng 2008;1:115-42.

63. Donaldson PE, Sayer E. A technology for implantable hermetic packages. Part 2: An implementation. Med Biol Eng Comput 1981; 19:403-5.

64. Cong P, Young DJ, Hoit B, Ko WH. Novel long-term implantable blood pressure monitoring system with reduced baseline drift. Conf Proc IEEE Eng Med Biol Soc 2006;1:1854-7.

65. Biffi M, Ziacchi M, Bertini M, Sangiorgi D, Corsini D, Martignani C, et al. Longevity of implantable cardioverter-defibrillators: implications for clinical practice and health care systems. Europace 2008; 10:1288-95.

66. Lanmuller H, Sauermann S, Unger E, Mayr W, Zrunek M. Batterypowered miniature implant for electrical nerve stimulation. Biomed Tech (Berl) 1999;44:114-9.

67. Seo H, Esashi M, Matsuo T. Manufacture of custom CMOS LSI for an implantable multipurpose biotelemetry system. Front Med Biol Eng 1989;1:319-29.

68. Do Valle B, Wentz CT, Sarpeshkar R. An area and power-efficient analog li-ion battery charger circuit. IEEE Trans Biomed Circuits Syst 2011;5:131-7.

69. Algora C, Pena R. Recharging the battery of implantable biomedical devices by light. Artif Organs 2009;33:855-60.

70. Tang Z, Sclabassi RJ, Sun C, Hackworth SA, Zhao J, Cui XT, et al.
Transcutaneous battery recharging by volume conduction and its circuit modeling. Conf Proc IEEE Eng Med Biol Soc 2006;1:644-7.

71. Lee SY, Hsieh CH, Yang CM. Wireless front-end with power management for an implantable cardiac microstimulator. IEEE Trans Biomed Circuits Syst 2012;6:28-38.

72. Duru F, Lauber P, Klaus G, Candinas R. Hospital pager systems may cause interference with pacemaker telemetry. Pacing Clin Electrophysiol 1998;21(11 Pt 2):2353-9.

73. Varosi SM, Brigmon RL, Besch EL. A simple remote-controlled power switch for internalized bioelectronic instrumentation. IEEE Trans Biomed Eng 1989;36:858-60.

74. Oncescu V, Erickson D. High volumetric power density, non-enzymatic, glucose fuel cells. Sci Rep 2013;3:1226.

75. Hashemi SS, Sawan M, Savaria Y. A high-efficiency low-voltage CMOS rectifier for harvesting energy in implantable devices. IEEE Trans Biomed Circuits Syst 2012;6:326-35.

76. Mitcheson PD. Energy harvesting for human wearable and implantable bio-sensors. Conf Proc IEEE Eng Med Biol Soc 2010; 2010:3432-6

77. Romero E, Warrington RO, Neuman MR. Energy scavenging sources for biomedical sensors. Physiol Meas 2009;30:R35-62.

78. Bhatia D, Bairagi S, Goel S, Jangra M. Pacemakers charging using body energy. J Pharm Bioallied Sci 2010;2:51-4.

79. Sardini E, Serpelloni M. Passive and self-powered autonomous sensors for remote measurements. Sensors 2009;9:943-60.

80. Goto H, Sugiura T, Harada Y, Kazui T. Feasibility of using the automatic generating system for quartz watches as a leadless pacemaker power source. Med Biol Eng Comput 1999;37:377-80.

81. Mazzilli F, Thoppay PE, Praplan V, Dehollaini C. Ultrasound energy harvesting system for deep implanted-medical-devices (IMDs). 2012 IEEE International Symposium on Circuits and Systems (ISCAS); 2012 May 20-23; Seoul, Korea. 2012. p. 2865-8.

82. Kerzenmachera S, Ducreeb J, Zengerle R, von Stettena F. Energy harvesting by implantable abiotically catalyzed glucose fuel cells. J Power Sources 2008;182:1-17.

83. Fang Q, Lee SY, Permana H, Ghorbani K, Cosic I. Developing a wireless implantable body sensor network in MICS band. IEEE Trans Inf Technol Biomed 2011;15:567-76.

84. Abouei J, Brown JD, Plataniotis KN, Pasupathy S. Energy efficiency and reliability in wireless biomedical implant systems. IEEE Trans Inf Technol Biomed 2011;15:456-66.

85. Parsa CJ, Daneshmand MA, Lima B, Balsara K, McCann RL, Hughes GC. Utility of remote wireless pressure sensing for endovascular leak detection after endovascular thoracic aneurysm repair. Ann Thorac Surg 2010;89:446-52. 